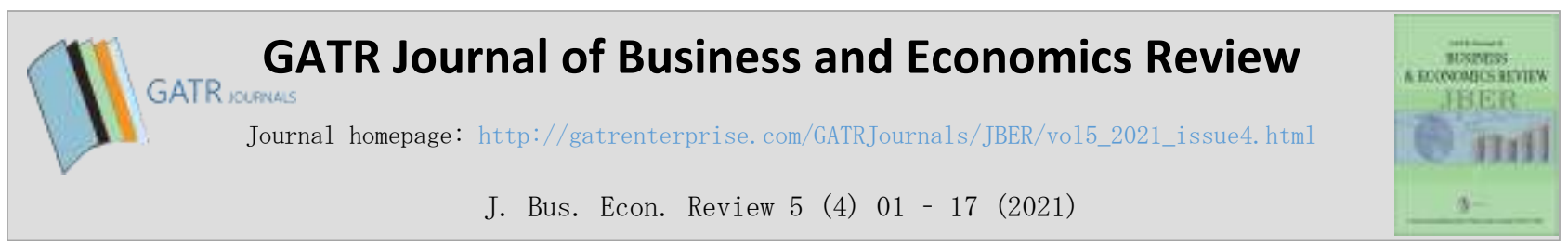

\title{
Building an Awareness Model of Emergency Supplies Dispatching for Tropical Cyclone Disasters*
}

\author{
Guoyou Yue ${ }^{1 *}$, Boonsub Panichakarn ${ }^{2}$ \\ ${ }^{1,2}$ Faculty of Logistics and Digital Supply Chain, Naresuan University, 99 Moo.9, Thapo, Mueang, 65000, Phitsanulok, Thailand
}

\begin{abstract}
Objective - The research objective of this paper is to establish an efficient awareness model of emergency supplies dispatching for tropical cyclone disasters, so as to timely deliver emergency supplies to each disaster area at the lowest cost.

Methodology/Technique - Taking the disaster caused by super typhoon No.1409 "Rammasun" to cities and counties in Guangxi as an example, 24 counties (districts) belonging to 7 prefecture-level cities with more than 1000 people in need of emergency transfer and resettlement are selected as the research objects.

Findings- The linear programming method is used to establish two kinds of emergency supplies dispatching models: level-by-level centralized dispatching model and unified dispatching model of provincial emergency management center. By comparing the calculation results of the two models, it is found that the level-by-level centralized dispatching model adopted by Guangxi government departments is relatively high in cost although it is simple and convenient.

Novelty- The total cost of the improved unified dispatching model of provincial emergency management center is $31.72 \%$ less than that of the level-by-level centralized dispatching model, which has greater promotion value. The research results can provide a better reference for the government departments at all levels in Guangxi to formulate the emergency supplies dispatching scheme for tropical cyclone disasters.
\end{abstract}

Type of Paper: Empirical.

JEL Classification: E24, J16.

Keywords: Emergency Logistics; Tropical Cyclone Disasters; Emergency Supplies Dispatching; Transportation Problem; Transshipment Problem; Linear Programming Model; Guangxi

Reference to this paper should be made as follows: Yue, G; Panichakarn, B. (2021). Building an Awareness Model of Emergency Supplies Dispatching for Tropical Cyclone Disasters, J. Bus. Econ. Review, 5(4) 01-17. https://doi.org/10.35609/jber.2021.5.4(1)

\section{Introduction}

It is found that Guangxi is affected by many tropical cyclones (generally referred to as typhoons in China) every year. According to the statistics of typhoons that entered the inland of Guangxi from 1970 to 2013, 89 typhoons entered Guangxi in 44 years, with an average of 2 typhoons per year (Jing Li, Liyan Qi, 2015). And these tropical cyclone disasters have caused a large number of casualties and economic losses in Guangxi. Typhoon No. 0606 "Prapiroon" entered Guangxi from Yulin city, causing 74 counties (cities and districts) in Guangxi to suffer disasters, affecting 5.76 million people, killing 34 people and causing direct economic losses of 7 billion yuan (Jing Li, et al., 2007).

\footnotetext{
* Paper Info: Revised: December 23, 2020

Accepted: March 31, 2021

* Corresponding author: Guoyou Yue E-mail: 563601374@qq.com

Affiliation: Faculty of Logistics and Digital Supply Chain, Naresuan University, Thailand
} 
In addition, according to the report of Guangxi Civil Affairs Department, super typhoon No. 1409 "Rammasun" landed in Fangchenggang area of Beibu Gulf, causing 4.3211 million people in 11 cities and 57 counties (cities and districts) including Beihai and Fangchenggang to suffer disaster, affecting 1.456 million hectares of crops, 8,527 farmhouses collapsed, and the direct economic losses reached 13.84 billion yuan. Moreover, the number and intensity of tropical cyclone that caused serious damage to Guangxi increased gradually. Just like the above two tropical cyclone disasters, the number of people affected by the disaster reached more than 4 million, and the number of damaged houses is also very large, causing a large number of affected people homeless. A large number of victims need governments and relief organizations at all levels to arrange temporary shelter and provide necessary emergency supplies. These emergency supplies need to be counted by governments and relief organizations at all levels according to the distribution and needs of the victims, and the governments and relief organizations at all levels should quickly raise the corresponding supplies and deliver them to the resettlement points of the victims in time.

Due to the wide distribution of the disaster areas caused by tropical cyclones, the amount of emergency supplies to ensure the basic living needs of the victims is very large. How to deliver the emergency supplies to the victims in time with the lowest transportation cost has become the key to the relief work. But emergency supplies dispatching involves a lot of problems, including the number of victims in the resettlement sites, the type and quantity of emergency supplies needed in the resettlement sites, the road connectivity and distance between the resettlement sites and the government emergency supplies reserves warehouses at all level, the quantity of emergency supplies stored in the government emergency supplies reserves warehouses at all level, and the vehicle information for the transportation of emergency supplies, etc. Therefore, it is necessary to actively raise all kinds of emergency supplies and make scientific and reasonable emergency supplies dispatching plans according to the respective responsibilities of governments and rescue organizations at all levels in the disaster areas. The problem to be solved in this paper is how to establish an efficient awareness model of emergency supplies dispatching to deliver all kinds of emergency supplies to the victims in time at the lowest cost for the severe tropical cyclone disaster in Guangxi, so as to improve the relief effect.

The rest of the paper is organized as follows. Section 2 gives a detailed literature review. It mainly includes the literature on Guangxi tropical cyclone disasters and emergency supplies dispatching model. Section 3 describes the methodology in detail. Linear programming method is used to establish the emergency supplies dispatching model under the balance of supply and demand. Section 4 describes the empirical analysis results and discussion in detail. The linear programming method is used to establish the emergency supplies dispatching models in two states, and the calculation results of the two models are compared and discussed. Section 5 summarizes the new findings and conclusions in empirical analysis.

\section{Literature review}

The literature review in this paper mainly involves tropical cyclone disaster, vehicle routing problem and emergency supplies dispatching model.

Every year, Guangxi is affected by several strong tropical cyclones, which cause great disasters to its economy and people. Jing $\mathrm{Li}$, et al. (2007) pointed that Typhoon No. 0606 "Prapiroon" entered Guangxi from Yulin city, causing 74 counties (cities and districts) to suffer disaster, with a population of 5.706 million, 34 people died in the disaster, and 7 billion yuan of direct economic loss in Guangxi. Yun Yu, et al. (2014) pointed that the strong super typhoon No. 1409 "Rammasun" has caused serious disasters to banana producing areas in Guangxi. It is suggested that active and effective post-disaster management should be carried out, the site should be chosen reasonably in the future production management, the consciousness of windbreak and wind resistance should be improved, and field management should be strengthened. Changfa Zhou \& Le Wang (2016) analyzed the damage that the strong super typhoon No. 1409 "Rammasun" cased to 
the transmission line in Guangxi, and further analysis and verification of the correctness of the basic wind speed values of a proposed transmission line. Zhuo Huang \& Xueping Liao (2017) pointed that the typhoon No. 1621 "Sarika" has the characteristics of a frontal attack on Guangxi with a wide range of wind and rain, and heavy local rainfall intensity. According to statistics from the civil affairs department of Guangxi Zhuang Autonomous Region at 20:00 on October 21, 2016, a total of 352,100 people were affected by the disaster in 6 cities and 20 counties (cities and districts) including Beihai, Fangchenggang, Nanning, Qinzhou, Chongzuo and Guigang. The disaster area of crops was $17.76 \times 1000 \mathrm{hm} 2$, of which the disaster area was $4.44 \times 1000$ hm2. 205 houses collapsed, 77 houses were seriously damaged, and 244 houses were generally damaged. Direct economic losses totaled 235 million yuan, including 124 million yuan in agricultural losses. Changyuan Wang et al. (2018) pointed that forty-six people were killed and 25 others are missing after floods, storms, mudslides, and other disasters occurred in "Rammasun", according to a statement on the ministry of civil affairs website and data from the civil affairs departments of Guangdong, Guangxi, Hainan and Yunnan provinces. In 144 counties (cities and districts), 9.966 million people were affected, 628,000 were relocated, and 252,000 needed emergency assistance. An area of 1,898.7 million hectares was affected by the disaster, of which 250.3 million hectares were lost. Direct economic losses amounted to 33.65 billion yuan. According to reports by the People's Daily Online, China News Network, International Online and the official website of affected provinces, losses were mainly in the following six areas: agriculture, forestry, animal husbandry and fishery, municipal facilities, industrial parks, collapsed residential buildings and traffic, ports and shipping.

There is a lot of literature on vehicle routing problem of emergency logistics. M. Desrochers et al. (1990) proposed a model classification scheme in the field of vehicle routing and scheduling based on four characteristics: address, vehicle, service strategy, and objective. Ajay K. Rathi et al. (1992) consider supply logistics in conflict or emergency situations. The authors develop LP models where routes and the amount of supply to be carried on each route are pre-determined between each origin-destination pair. Their problem is to identify the optimal number of vehicles to be assigned to each route and the problem becomes an assignment problem. Luisa Equi et al. (1997) consider a combined transportation and scheduling problem in a supply chain where the transportation problem aims to identify the optimal number of trips to satisfy demand (customers) from a given number of supply nodes (plants). The scheduling problem, on the other hand, identifies the number of trucks (of homogeneous capacity) that has to be allocated to make the trips. Again, the routes are pre-specified and a vehicle assignment problem is solved rather than a routing problem. Rodrigo A. Garrido, et al. (2015) presents a model to assist decision makers in the logistics of a flood emergency. The model attempts to optimize inventory levels for emergency supplies as well as vehicles' availability, in order to deliver enough supplies to satisfy demands with a given probability. Nariman Nikoo, et al. (2018) proposed the emergency transportation network design problem to determine the optimal network to perform emergency response trips with high priority in the aftermath of earthquakes. The problem has three objective functions designated to identify the optimal routes for emergency vehicles considering the length, the travel time and the number of paths as performance metrics of network vulnerability.

There are many applicable conditions and methods for the emergency supplies dispatching model, and different emergency supplies dispatching methods can be adopted for different dispatching needs. Linet Özdamar et al. (2004) developed a planning model which addresses the dynamic time-dependent transportation problem that needs to be solved repetitively at given time intervals during ongoing aid delivery. Cheng Miao (2007) analyzed the transportation of many kinds of materials, each kind of goods may have multiple supply points and demand points, the supply and demand of materials, The location of supply and demand will change, vehicles can appear at any point in the supply network, the number is limited and changes with time and so on. Based on the network flow model, the mixed integer programming model of relief material transportation and vehicle scheduling is established. Based on the Lagrangian relaxation 
method, a drawing transportation scheduling algorithm is designed to solve the approximate optimal solution of the model. Tirado et al. (2014) use a lexicographic approach to manage the delivery of relief, using a twophase flow model. At the first level, the difference between the aid planned to be shipped and the aid sent in reality is minimized. And time, cost and the highest unsatisfied demand is dealt with in the second phase. Also, considering the need to undertake repairs for subsequent distribution, Liberatore et al. (2014) present a distribution-recovery model for disasters, with the objective of maximizing the total reached demand, minimizing the maximum distance from reliability, security, and demand satisfaction from its ideal value, and minimizing the sum of the attribute distances. Meanwhile, Shalei Zhang, et al. (2014) incorporate stochastic demands, reliability of the distribution network and Bayesian updates for disaster scenario information. The model proposed minimizes total time, unmet demand, and cost. Oscar Rodríguez-espíndola, at al. (2018) contributed to the resource allocation challenge by examining shortages and excess. To design a dynamic optimization model to support relief distribution and resource allocation which incorporates resources from multiple organizations.

Through the analysis of the above literatures, it is shown that emergency supplies dispatching under the condition of emergency has always been the focus of research on emergency logistics in various countries. At present, all kinds of emergency logistics resources in China are still being integrated and perfected, especially there is still a certain gap between Guangxi and developed provinces in emergency logistics management. The above literature results do not know much about the emergency supplies dispatching of tropical cyclone disasters in Guangxi, and lack of a scientific and reasonable dispatching model. The influence scope of tropical cyclone disasters in Guangxi is big, provincial, municipal and county governments at all levels have built emergency supplies reserves warehouse coexist with different kinds and number of emergency supplies, transportation lines and distance between all levels of emergency supplies reserves warehouse are different, various municipal cities and counties are generally only responsible for the jurisdiction within the scope of the emergency supplies planning and dispatching. Because of these effect factors of emergency supplies dispatching for tropical cyclone disasters in Guangxi, so it is necessary to establish a highly efficient and low cost awareness model of emergency supplies dispatching for tropical cyclone disasters in Guangxi. It provides reference for Guangxi government emergency management departments at all levels to formulate emergency rescue plan for tropical cyclone disasters.

\section{Methodology}

The emergency supplies dispatching for tropical cyclone disaster in Guangxi is a transshipment problem of emergency supplies involving multi-supply nodes, multi-transfer nodes and multi-demand nodes of the province, municipality and county three levels. This problem is also a special subproblem of the transportation problem that require timely delivery of emergency supplies to victims at minimum cost. The linear programming model to solve this problem can be expressed as:

$$
\min f=\sum_{i=1}^{m} \sum_{j=1}^{n} c_{i j} x_{i j}
$$

The constraints are as follows:

For provincial emergency supplies storage warehouse: $\sum_{j=1}^{n} x_{i j}=s_{i}$

For municipal emergency supplies storage warehouse: $\sum_{\text {all-out }} x_{i j}-\sum_{\text {all-in }} x_{i j}-M_{0 i}=0$

For county level emergency supplies storage warehouse: $\sum_{i=1}^{m} x_{i j}+D_{0 j}=d_{j}$ 
For the amount of emergency supplies originally stored in each municipal emergency supplies reserve warehouse: $M_{0 i} \geq 0(i=1,2, \ldots, m)$

For the amount of emergency supplies originally stored in each county level emergency supplies reserve warehouse: $D_{0 j} \geq 0(j=1,2, \ldots, n)$

For transfers of emergency supplies between all nodes: $x_{i j} \geq 0(i=1,2, \ldots, m ; j=1,2, \ldots, n)$

Among them,

$x_{i j}$ - represents the transferred volume from node $i$ to node $j$.

$c_{i j}$ - represents the unit freight rate from node $i$ to node $j$.

$s_{i}$ - represents the total supply of emergency supplies provided by the provincial emergency supplies reserve warehouse.

$M_{0 i}$ - represents the amount of emergency supplies originally stored in the municipal emergency supplies reserve warehouse.

$D_{0 j}$ - represents the amount of emergency supplies originally stored in the county level emergency supplies reserve warehouse.

$d_{j}$ - represents the total demand of emergency supplies needed by the county level emergency supplies reserve warehouse.

\section{Results and discussion}

Each tropical cyclone will have different impacts on different cities in Guangxi, and the severity of the disaster varies from region to region. However, the methods and models for emergency supplies dispatching are the same. Super typhoon No. 1409 "Rammasun" was selected as an example to establish the emergency supplies dispatching model for tropical cyclone disasters.

\subsection{The disaster situation in the main disaster areas, the demand and reserve of emergency supplies}

According to the statistical yearbook 2014 for tropical cyclone data shows, super typhoon No. 1409 "Rammasun" has caused a serious loss to Guangxi, the main disaster area ranging from Beihai, Qinzhou, Fangchenggang, Yulin, Nanning, Chongzuo, Wuzhou and other seven cities as 47 units at the county level, within the scope of the jurisdiction of the affected population of 4.33 million people, 10 deaths, emergency relocated population of 320000 people, the affected area of 777300 hectares of crops, crop lost area of 40400 hectares, 10000 houses collapsed, the direct economic loss of 13.9 billion RMB yuan.

According to the survey statistics data of affected population caused by super typhoon No. 1409 "Rammasun" from the Emergency Management Hall in Guangxi, selecting need emergency relocated population of more than 1000 units at the county level as the research object. A total of 24 units at the county level are in need of urgent to relocate a population of more than 1000 people. And the 24 units at the county level belong to Nanning, Qinzhou, Beihai, Fangchenggang, Chongzuo, Yulin and Wuzhou. The rest of the affected less the number of units at the county level are not counted. The specific node number of each provincial, prefecture-level and county-level unit and the number of people affected at each node are shown in Table 1.

Table 1. Disasters, demand and reserve emergency supplies caused by "Rammasun" in Guangxi. 


\begin{tabular}{|c|c|c|c|c|c|c|c|}
\hline $\begin{array}{l}\text { Number } \\
\text { of } \\
\text { disaster } \\
\text { units }\end{array}$ & Name of disaster units & $\begin{array}{c}\text { Affected } \\
\text { population } \\
\text { (person) }\end{array}$ & $\begin{array}{l}\text { Emergency } \\
\text { resettlement of } \\
\text { population } \\
\text { (person) }\end{array}$ & $\begin{array}{l}\text { Population in } \\
\text { need of } \\
\text { emergency } \\
\text { assistance } \\
\text { (person) }\end{array}$ & $\begin{array}{l}\text { Population } \\
\text { in need of } \\
\text { transitional } \\
\text { assistance } \\
\text { (person) }\end{array}$ & $\begin{array}{c}\text { Total } \\
\text { demand of } \\
\text { emergency } \\
\text { supplies } \\
\text { (ton) }\end{array}$ & $\begin{array}{l}\text { Quantity of } \\
\text { emergency } \\
\text { supplies in } \\
\text { reserve (ton) }\end{array}$ \\
\hline 1 & Guangxi & 3351465 & 314190 & 192430 & 27450 & 4395 & 3514 \\
\hline 2 & Nanning city & 34041 & 1805 & 1499 & 186 & 32 & 20 \\
\hline 11 & LiangQing district & 34041 & 1805 & 1499 & 186 & 32 & 0 \\
\hline 3 & Qinzhou city & 1252020 & 90650 & 35088 & 4386 & 745 & 100 \\
\hline 12 & Qinbei district & 392000 & 24243 & 9756 & 619 & 153 & 24 \\
\hline 13 & Qinnan district & 389583 & 47843 & 15110 & 1891 & 321 & 20 \\
\hline 14 & Lingshan county & 399600 & 11316 & 6650 & 103 & 76 & 8 \\
\hline 15 & Pubei county & 70837 & 7248 & 3572 & 1773 & 195 & 12 \\
\hline 4 & Beihai city & 530391 & 88017 & 71330 & 5536 & 1212 & 160 \\
\hline 16 & Haicheng district & 135000 & 12850 & 11830 & 672 & 179 & 40 \\
\hline 17 & Yinhai district & 94500 & 23000 & 18000 & 652 & 239 & 26 \\
\hline 18 & Tieshanggang district & 90000 & 16000 & 11000 & 412 & 147 & 20 \\
\hline 19 & Hepu county & 210891 & 36167 & 30500 & 3800 & 647 & 35 \\
\hline 5 & Fangchengang city & 614584 & 85654 & 74995 & 12905 & 1911 & 120 \\
\hline 20 & Dongxing city & 26000 & 5800 & 1355 & 355 & 46 & 10 \\
\hline 21 & Shangshi county & 106000 & 18487 & 40000 & 8961 & 1206 & 25 \\
\hline 22 & Gangkou district & 156084 & 30557 & 21830 & 1763 & 377 & 30 \\
\hline 23 & Fangchen district & 326500 & 30810 & 11810 & 1826 & 282 & 20 \\
\hline 6 & Chongzhuo city & 693314 & 30658 & 3982 & 2447 & 260 & 50 \\
\hline 24 & Longzhou county & 61555 & 9175 & 690 & 270 & 31 & 10 \\
\hline 25 & Pingxiang city & 43165 & 1640 & 732 & 2134 & 199 & 20 \\
\hline 26 & Ningming county & 231670 & 14587 & 977 & 0 & 10 & 2 \\
\hline 27 & Fusui county & 231430 & 2401 & 0 & 43 & 4 & 1 \\
\hline 28 & Jiangzhou district & 125494 & 2855 & 1583 & 0 & 16 & 5 \\
\hline 7 & Yulin city & 198697 & 13146 & 3992 & 1264 & 154 & 40 \\
\hline 29 & Fuming district & 26516 & 2657 & 326 & 0 & 3 & 1 \\
\hline 30 & Luchuan county & 15000 & 1520 & 312 & 0 & 3 & 1 \\
\hline 31 & Bobai county & 136641 & 6891 & 3004 & 1264 & 144 & 35 \\
\hline 32 & Yuzhou district & 20540 & 2078 & 350 & 0 & 4 & 2 \\
\hline 8 & Wuzhou city & 28418 & 4260 & 1544 & 726 & 81 & 20 \\
\hline 33 & CenXi city & 16789 & 1713 & 782 & 341 & 39 & 10 \\
\hline 34 & Cangwu county & 11629 & 2547 & 762 & 385 & 42 & 14 \\
\hline
\end{tabular}

According to the notice on adjusting the subsidy standard for natural disaster relief issued by the Department of Civil Affairs and The Department of Finance of Guangxi Zhuang Autonomous Region, the subsidy standard for people in need of emergency living assistance shall be no more than 400 RMB yuan per person, and the longest period of assistance shall not exceed 10 days. The actual subsidy shall be calculated as 10 days. Each person receiving transitional assistance will receive a subsidy of 25 RMB yuan per day for a period not exceeding 3 months, and the actual subsidy will be calculated on the basis of 90 days in 3 months. All kinds of emergency supplies such as food, drinking water, the peripheral convert about need $1 \mathrm{~kg}$ per person per day, according to the standard to calculate all kinds of emergency supplies demand quantity, for the convenience of calculation results is rounded, emergency supplies around the demand quantity as shown in Table 1, other aid, according to the standard of relief in the form of cash to the affected people. 
The emergency supplies dispatching in Guangxi adopts the three-level management mode of provincial level, prefecture level city and county. There is one disaster preparedness center in Guangxi Zhuang Autonomous Region at the provincial level, one main emergency supplies reserve warehouse in each prefecture level city, and one emergency supplies reserve warehouse in each county level unit. See Table 1 for the amount of emergency supplies stored in the emergency supplies reserve warehouses at all levels. Through traffic and Baidu map query to Guangxi provincial emergency supplies reserves warehouses of the Guangxi Zhuang Autonomous Region disaster preparedness center with the affected the distance between prefecture and county units, and each affected under the jurisdiction of the prefecture level and the distance between the county units, and in accordance with the highway cargo tariff of the People's Republic of China highway freight unit price is $0.35 \mathrm{RMB}$ yuan/ton $\bullet \mathrm{km}$, multiplied by the distance between the around with highway freight unit price between freight unit price, for the convenience of calculating all freight unit price is rounded. The specific calculation results are shown in Table 2.

Table 2. Freight unit price between emergency supplies storage warehouses.

\begin{tabular}{|c|c|c|c|c|c|c|c|c|}
\hline Number of disaster units & 1 & 2 & 3 & 4 & 5 & 6 & 7 & 8 \\
\hline 2 & 4 & & & & & & & \\
\hline 3 & 41 & & & & & & & \\
\hline 4 & 78 & & & & & & & \\
\hline 5 & 47 & & & & & & & \\
\hline 6 & 44 & & & & & & & \\
\hline 7 & 96 & & & & & & & \\
\hline 8 & 132 & & & & & & & \\
\hline 11 & 3 & 3 & & & & & & \\
\hline 12 & 41 & & 1 & & & & & \\
\hline 13 & 46 & & 5 & & & & & \\
\hline 14 & 44 & & 36 & & & & & \\
\hline 15 & 58 & & 53 & & & & & \\
\hline 16 & 77 & & & 1 & & & & \\
\hline 17 & 77 & & & 1 & & & & \\
\hline 18 & 81 & & & 13 & & & & \\
\hline 19 & 68 & & & 10 & & & & \\
\hline 20 & 61 & & & & 16 & & & \\
\hline 21 & 33 & & & & 37 & & & \\
\hline 22 & 49 & & & & 3 & & & \\
\hline 23 & 46 & & & & 4 & & & \\
\hline 24 & 63 & & & & & 22 & & \\
\hline 25 & 69 & & & & & 28 & & \\
\hline 26 & 57 & & & & & 17 & & \\
\hline 27 & 24 & & & & & 26 & & \\
\hline 28 & 42 & & & & & 2 & & \\
\hline 29 & 99 & & & & & & 3 & \\
\hline 30 & 118 & & & & & & 15 & \\
\hline 31 & 106 & & & & & & 16 & \\
\hline 32 & 96 & & & & & & 1 & \\
\hline 33 & 125 & & & & & & & 29 \\
\hline 34 & 126 & & & & & & & 5 \\
\hline
\end{tabular}




\subsection{Construct the emergency supplies dispatching model}

The emergency supplies dispatching model usually adopts the level-by-level centralized dispatching model or the unified dispatching model of the provincial emergency management center.

\subsubsection{Level-by-level centralized dispatching model}

According to the statistics on disaster relief and relief caused by super typhoon No.1409 "Rammasun" to all cities and counties in Guangxi, the provincial, municipal and county management system is usually adopted for the storage and distribution of emergency supplies in Guangxi. The emergency management department at the county level is the management organ of the grassroots government, responsible for the implementation of disaster relief work within the county. The specific principles of emergency supplies are as follows. First, the emergency management department at the county level shall provide the relief supplies needed by the victims according to the situation of the emergency supplies reserve warehouse at the county level, and the insufficient part shall be reported to the emergency management department of the prefecture government. Then, the prefecture government shall make statistics on the insufficient demand for emergency supplies in each county under its jurisdiction, and the prefecture emergency supplies reserve warehouse shall try to meet the shortage according to the supplies reserve, and the insufficient part shall be reported to the emergency management department of the provincial government. Finally, emergency management department at the provincial level statistics of various cities to declare the shortage of the emergency supplies demand, warehouse according to the materials by provincial emergency supplies reserves situation as far as possible to meet, skimpy share the Emergency Management Hall at the provincial level shall be responsible for the centralized purchasing all kinds of emergency supplies, and are issued by the number of cities all kinds of emergency supplies to declare emergency supplies.

According to the above analysis, the Network diagram of the level-by-level centralized dispatching model for emergency supplies in Guangxi is shown in Figure 1.

According to Figure 1 with transshipment model of intermediate nodes, $x_{i j}$ means from point $i$ to point $j$ emergency supplies carrying quantity. Such as $x_{13}$ represents the dispatching quantity from the provincial level node 1 Disaster Preparedness Center of Guangxi Zhuang Autonomous Region to the prefecture level node 3 Qinzhou emergency supplies storage warehouse. And ${ }^{x_{419}}$ represents the dispatching quantity from the prefecture level node 4 Beihai emergency supplies storage warehouse to the county level node 19 Hepu county emergency supplies storage warehouse. And the number on the line represents the freight unit price between the two nodes. And the number 3514 on the top of node 1 represents the total supply quantity of provincial level Disaster Preparedness Center. And the number on the top of node 2 to 8 represents the reserves in each prefecture level warehouse. And the first number on the right of node 11 to 34 represents the demand quantity of each county level warehouse, and the second number on the right of node 11 to 34 represents the reserves in each county level warehouse. 


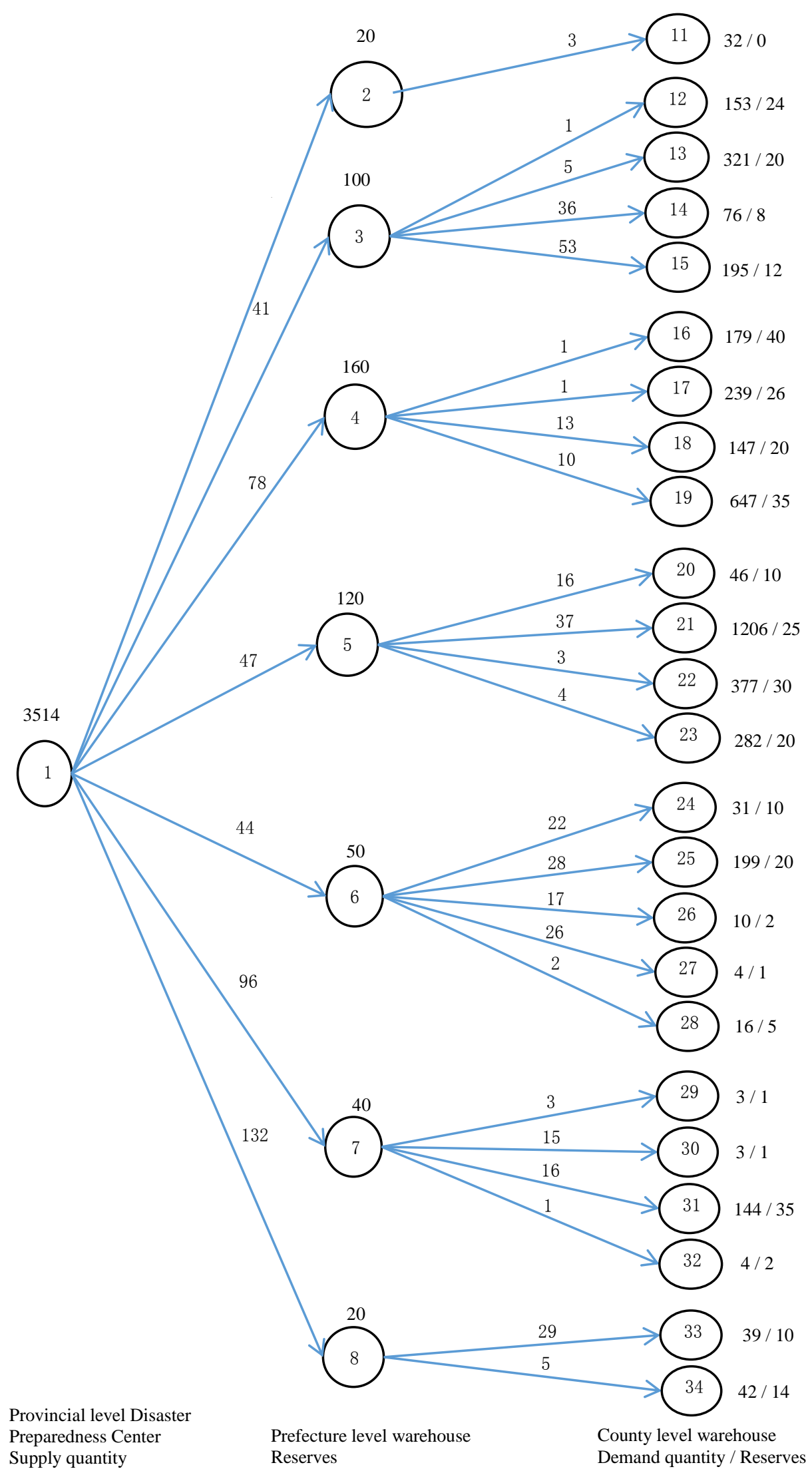

J. Bus. Econ. Review 5 (4) 01 - 17 (2021) 
Figure 1. Network diagram of level-by-level centralized dispatching model for emergency supplies in Guangxi

The linear programming model to solve the level-by-level centralized dispatching model for emergency supplies in Guangxi as follows. The objective function of the minimum dispatching cost under this dispatching model is:

$$
\begin{aligned}
\min f_{1} & =4 x_{12}+41 x_{13}+78 x_{14}+47 x_{15}+44 x_{16}+96 x_{17}+132 x_{18}+3 x_{211}+x_{312}+5 x_{313} \\
& +36 x_{314}+53 x_{315}+x_{416}+x_{417}+13 x_{418}+10 x_{419}+16 x_{520}+37 x_{521}+3 x_{522}+4 x_{523} \\
& +22 x_{624}+28 x_{625}+17 x_{626}+26 x_{627}+2 x_{628}+3 x_{729}+15 x_{730}+16 x_{731}+x_{732} \\
& +29 x_{833}+5 x_{834}
\end{aligned}
$$

S.t. :

$$
\begin{aligned}
& x_{12}+x_{13}+x_{14}+x_{15}+x_{16}+x_{17}+x_{18} \leq 3514, \\
& x_{211}-x_{12}-20=0, \\
& x_{312}+x_{313}+x_{314}+x_{315}-x_{13}-100=0, \\
& x_{416}+x_{417}+x_{418}+x_{419}-x_{14}-160=0, \\
& x_{520}+x_{521}+x_{522}+x_{235}-x_{15}-120=0, \\
& x_{624}+x_{625}+x_{626}+x_{627}+x_{628}-x_{16}-50=0, \\
& x_{729}+x_{730}+x_{731}+x_{732}-x_{17}-40=0, \\
& x_{833}+x_{834}-x_{18}-20=0, \\
& x_{211}+0=32, \\
& x_{312}+24=153, \\
& x_{313}+20=321, \\
& x_{314}+8=76, \\
& x_{315}+12=195, \\
& x_{416}+40=179, \\
& x_{417}+26=239, \\
& x_{418}+20=147, \\
& x_{419}+35=647, \\
& x_{520}+10=46, \\
& x_{521}+25=1206, \\
& x_{522}+30=377, \\
& x_{523}+20=282, \\
& x_{624}+10=31, \\
& x_{625}+20=199, \\
& x_{626}+2=10, \\
& x_{627}+1=4, \\
& x_{628}+5=16, \\
&
\end{aligned}
$$




$$
\begin{aligned}
& x_{729}+1=3, \\
& x_{730}+1=3, \\
& x_{731}+35=144, \\
& x_{732}+2=4, \\
& x_{833}+10=39, \\
& x_{834}+14=42, \\
& x_{i j} \geq 0(i=1,2,3,4,5,6,7,8 ; j=2,3,4,5,6,7,8,11,12,13, \cdots \cdots, 34)
\end{aligned}
$$

The calculated results are as follows:

$$
\begin{aligned}
& x_{12}=12, x_{13}=581, x_{14}=931, x_{15}=1706, x_{16}=172, x_{17}=75, x_{18}=37, \\
& x_{211}=32, x_{312}=129, x_{313}=301, x_{314}=68, x_{315}=183, x_{416}=139, \\
& x_{417}=213, x_{418}=127, x_{419}=612, x_{520}=36, x_{521}=1181, x_{522}=347, \\
& x_{523}=262, x_{624}=21, x_{625}=179, x_{626}=8, x_{627}=3, x_{628}=11, x_{729}=2, \\
& x_{730}=2, x_{731}=109, x_{732}=2, x_{833}=29, x_{834}=28 .
\end{aligned}
$$

The dispatching quantity between the above nodes is substituted into the objective function to obtain the minimum dispatching cost of 272,651 RMB yuan.

\subsubsection{Unified dispatching model of provincial emergency management center}

According to the comparison of data in Table 2, the freight rates of units directly supplying emergency supplies to the emergency storage warehouse at the county level of disaster areas by the provincial disaster preparedness center are lower than the unit price of the level-by-level dispatching model, which is transferred from the provincial level to the prefecture level city and then to the county level. Therefore, it is cheaper and more time efficient to change the level-by-level centralized dispatching model into the provincial level disaster preparedness center to supply the emergency supplies directly to the county level emergency stores. Emergency supplies stored in prefecture level cities shall also be transferred directly to emergency supplies storage warehouse at the county level within their jurisdiction. The network diagram of unified dispatching model of provincial emergency management center for emergency supplies in Guangxi is shown in Figure 2.

According to Figure 2 with transshipment model, the biggest difference between this model and the levelby-level dispatching model is that the provincial disaster preparedness center directly sends the emergency supplies to the disaster county level units instead of passing through the prefecture level warehouse, which greatly improves the rescue efficiency and reduces the transport cost. In this model, $x_{i j}$ means from point $i$ to point $j$ emergency supplies carrying quantity. Such as $x_{112}$ represents the dispatching quantity from the provincial level node 1 Disaster Preparedness Center to the county level node 12 Qinbei district emergency supplies storage warehouse. And ${ }^{x_{119}}$ represents the dispatching quantity from the prefecture level node 4 Beihai emergency supplies storage warehouse to the county level node 19 Hepu county emergency supplies storage warehouse. And the number on the line represents the freight unit price between the two nodes. And the number 3514 on the top of node 1 represents the total supply quantity of provincial level Disaster Preparedness Center. And the number on the top of node 2 to 8 represents the reserves in each prefecture level warehouse. And the first number on the right of node 11 to 34 represents the demand quantity of each 


\section{Guoyou Yue and Boonsub Panichakarn}

county level warehouse, and the second number on the right of node 11 to 34 represents the reserves in each county level warehouse. 


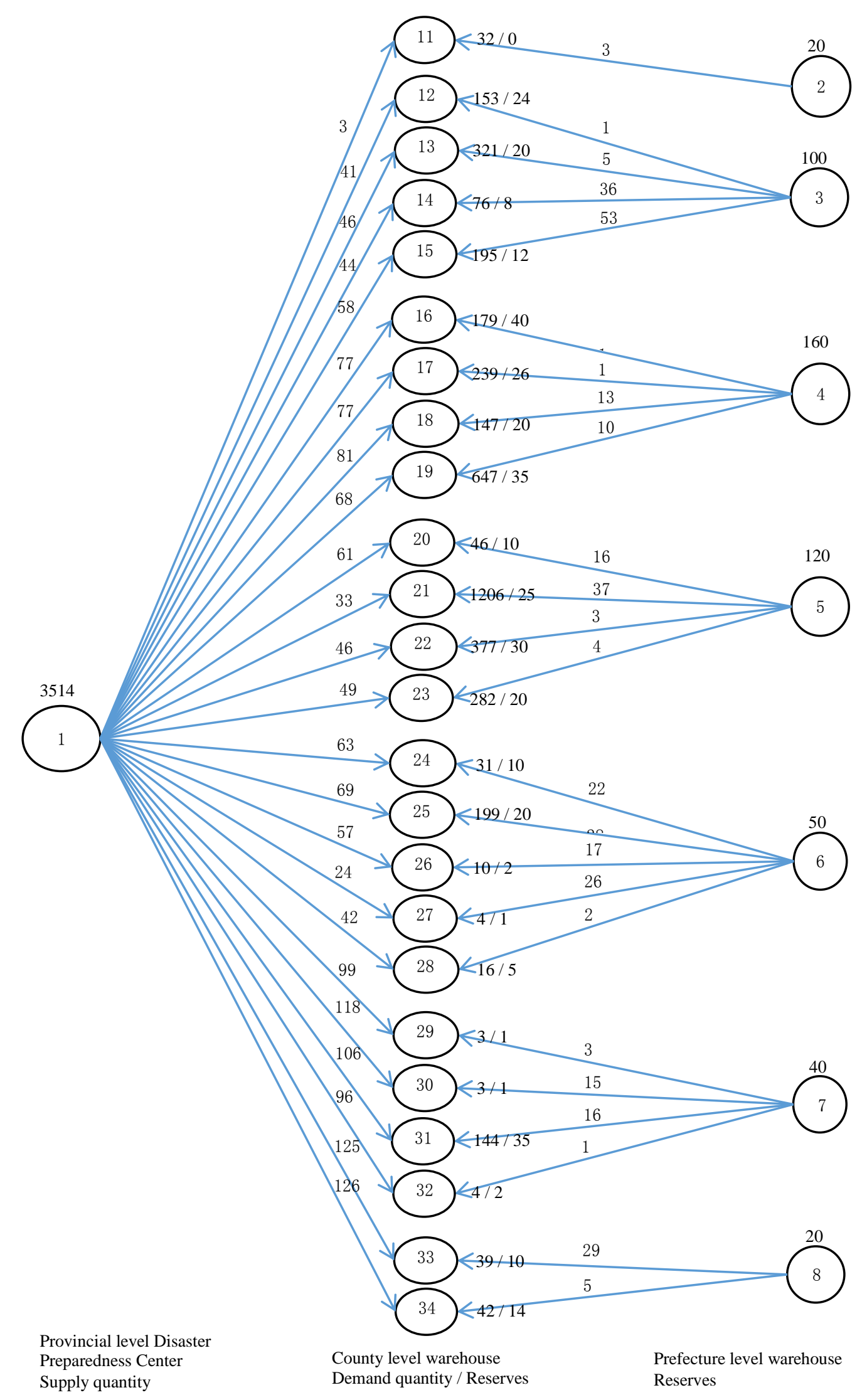

J. Bus. Econ. Review 5 (4) 01 - 17 (2021) 
Figure 2. Network diagram of unified dispatching model of provincial emergency management center for emergency supplies in Guangxi

In the same way, the linear programming model to solve unified dispatching model of provincial emergency management center for emergency supplies in Guangxi as follows. The objective function of the minimum dispatching cost under this dispatching model is:

$$
\begin{aligned}
\min f_{2} & =3 x_{111}+41 x_{112}+46 x_{113}+44 x_{114}+58 x_{115}+77 x_{116}+77 x_{117}+81 x_{118} \\
& +68 x_{119}+61 x_{120}+33 x_{121}+49 x_{122}+46 x_{123}+63 x_{124}+69 x_{125}+57 x_{126}+24 x_{127} \\
& +42 x_{128}+99 x_{129}+118 x_{130}+106 x_{131}+96 x_{132}+125 x_{133}+126 x_{134}+3 x_{211}+x_{312} \\
& +5 x_{313}+36 x_{314}+53 x_{315}+x_{416}+x_{417}+13 x_{418}+10 x_{419}+16 x_{520}+37 x_{521}+3 x_{522} \\
& +4 x_{523}+22 x_{624}+28 x_{625}+17 x_{626}+26 x_{627}+2 x_{628}+3 x_{729}+15 x_{730}+16 x_{731}+x_{732} \\
& +29 x_{833}+5 x_{834}
\end{aligned}
$$

S.t.:

$$
\begin{aligned}
& x_{111}+x_{112}+x_{113}+x_{114}+x_{115}+x_{116}+x_{117}+x_{118}+x_{119}+x_{120}+x_{121}+x_{122} \\
& +x_{123}+x_{124}+x_{125}+x_{126}+x_{127}+x_{128}+x_{129}+x_{130}+x_{131}+x_{132}+x_{133}+x_{134}=3514 \\
& x_{211}=20 \\
& x_{312}+x_{313}+x_{314}+x_{315}=100 \\
& x_{416}+x_{417}+x_{418}+x_{419}=160 \\
& x_{520}+x_{521}+x_{522}+x_{235}=120 \\
& x_{624}+x_{625}+x_{626}+x_{627}+x_{628}=50 \\
& x_{729}+x_{730}+x_{731}+x_{732}=40 \\
& x_{833}+x_{834}=20 \\
& x_{111}+x_{211}+0=32 \\
& x_{112}+x_{312}+24=153 \\
& x_{113}+x_{313}+20=321 \\
& x_{114}+x_{314}+8=76 \\
& x_{115}+x_{315}+12=195 \\
& x_{116}+x_{416}+40=179 \\
& x_{117}+x_{417}+26=239 \\
& x_{118}+x_{418}+20=147 \\
& x_{119}+x_{419}+35=647 \\
& x_{120}+x_{520}+10=46 \\
& x_{121}+x_{521}+25=1206 \\
& x_{122}+x_{522}+30=377 \\
& x_{123}+x_{523}+20=282 \\
&
\end{aligned}
$$




$$
\begin{aligned}
& x_{124}+x_{624}+10=31, \\
& x_{125}+x_{625}+20=199, \\
& x_{126}+x_{626}+2=10, \\
& x_{127}+x_{627}+1=4, \\
& x_{128}+x_{628}+5=16, \\
& x_{129}+x_{729}+1=3, \\
& x_{130}+x_{730}+1=3, \\
& x_{131}+x_{731}+35=144, \\
& x_{132}+x_{732}+2=4, \\
& x_{133}+x_{833}+10=39, \\
& x_{134}+x_{834}+14=42, \\
& x_{i j} \geq 0(i=1,2,3,4,5,6,7,8 ; j=11,12,13, \cdots \cdots, 34)
\end{aligned}
$$

The calculated results are as follows:

$$
\begin{aligned}
& x_{111}=12, x_{112}=129, x_{113}=201, x_{114}=68, x_{115}=183, x_{116}=0, x_{117}=192, \\
& x_{118}=127, x_{119}=612, x_{120}=36, x_{121}=1181, x_{122}=227, x_{123}=262, x_{124}=0, \\
& x_{125}=150, x_{126}=8, x_{127}=3, x_{128}=11, x_{129}=0, x_{130}=0, x_{131}=75, x_{132}=0, \\
& x_{133}=29, x_{134}=8, x_{211}=20, x_{312}=0, x_{313}=100, x_{314}=0, x_{315}=0, \\
& x_{416}=139, x_{417}=21, x_{418}=0, x_{419}=0, x_{520}=0, x_{521}=0, x_{522}=120, x_{523}=0, \\
& x_{624}=21, x_{625}=29, x_{626}=0, x_{627}=0, x_{628}=0, x_{729}=2, x_{730}=2, x_{731}=34, \\
& x_{732}=2, x_{833}=0, x_{834}=20 .
\end{aligned}
$$

The dispatching quantity between the above nodes is substituted into the objective function to obtain the minimum dispatching cost of 186,167 RMB yuan.

\subsection{Discussion}

At present, governments at all levels in Guangxi usually adopt the level-by-level centralized dispatching model when carrying out emergency supplies dispatching. This model can better define the relationship between governments at all levels, and governments at all levels can better control the reasonable distribution of emergency supplies within their jurisdiction. However, this model will have a certain time delay in information communication, and there may be some unreasonable transportation conditions such as detour in the dispatch of emergency supplies between the emergency supplies storage warehouses of governments at all levels. Therefore, it takes more time and cost to raise and dispatch emergency supplies.

The improved unified dispatching model of provincial emergency management center is more efficient. This model can directly transfer emergency supplies between the provincial emergency management center and the county emergency materials storage warehouse, which eliminates the transfer link of the advanced emergency supplies warehouse, and greatly improves the efficiency of emergency supplies dispatching. The emergency supplies dispatching requires less time and costs.

Comparing the two emergency supplies dispatching models, the freight saved in unified dispatching model of provincial emergency management center is: $272651-186167=86,484 \mathrm{RMB}$ yuan, and the saving ratio is: 
$(86,484 / 272651) * 100 \%=31.72 \%$. The saving effect is obvious, and unified dispatching model of provincial emergency management center is more feasible.

\section{Conclusions}

By consulting literature, yearbooks and other historical data, and combining with interviews and investigations with emergency management departments of governments at all levels, this paper has a deeper understanding of the division of labor and cooperation in emergency rescue of emergency management departments of governments at all levels in the face of severe tropical cyclone disasters. Representative results and findings include:

First, Guangxi adopts the provincial, municipal and county three level government emergency management system. Emergency management departments of governments at lower levels shall be responsible to emergency management departments at higher levels.

Second, emergency management departments of governments at all levels have their own emergency supplies storage warehouses and designated procurement suppliers. According to the different disaster damage situation, it can feedback the damage situation and the amount of emergency supplies from county level, municipal level and provincial level.

Third, the emergency management department of the county-level government is the forefront command force of emergency rescue, which can provide relief to the victims in the first time according to the disaster loss, greatly improving the timeliness of rescue.

Fourth, the connectivity of transportation infrastructure among provinces, municipalities and counties directly affects the timeliness of the formulation of emergency supplies dispatching plan, as well as the cost of emergency supplies dispatching.

By building the awareness model of emergency supplies dispatching for tropical cyclone disasters in Guangxi, it can help the provincial, municipal and county government emergency management departments to formulate the emergency supplies dispatching scheme quickly and deliver the emergency supplies to the victims timely at the minimum cost. The following conclusions can be drawn from the model calculation:

First, the emergency management departments of the municipal and county governments may, in the light of the disasters within their jurisdiction, dispatch emergency supplies stored in the storage warehouses of emergency supplies at the corresponding level in the first time to help the disaster-stricken people.

Second, the emergency management department of the provincial government can make a unified summary, unified procurement, and unified dispatching scheme of emergency supplies according to the situation of the disaster victims and the needs of various emergency supplies as reported by the emergency management department of each municipal and county, so as to ensure the goal of minimizing the emergency rescue cost. The unified dispatching mode of provincial emergency management center is adopted.

Third, the selection of transportation routes among the nodes of provinces, municipalities and counties determines the unit price of transportation among nodes, and the selection of optimal transportation routes will effectively reduce the total cost of the entire emergency supplies dispatching scheme.

Fourth, the two dispatching models can quickly adjust and form appropriate emergency supplies dispatching plans according to different locations and disaster levels, with good flexibility and promotion value.

\section{Acknowledgements}

This work is supported by the Financial Support Criteria for Thesis and Oral Presentations Given in National or International Conferences of Graduate Students of the Faculty of Logistics and Digital Supply Chain, Naresuan University. And supported by the fund for cultivating young and middle-aged academic 
leaders of Guangxi University of Finance and Economics. And supported by the "Big Data + Emergency Logistics" team, the second innovation team of Guangxi University of Finance and Economics. And Supported by the Management Science and Engineering discipline construction fund of Guangxi University of Finance and Economics.

\section{References}

Rathi, A. K., Church, R. L., \& Solanki, R. S. (1992). Allocating resources to support a multicommodity flow with time windows. The Logistics and Transportation Review, 28(2), 167-189.https://doi.org/10.1016/0022-4375(92)90027-7.

Changfa Zhou, Le Wang. (2016). Analysis and Demonstration on Basic Wind Speed Value of an Overhead Transmission Line in Guangxi Coastal Area Affected by Severe Typhoon Rammasun. Hong Shui River, 35(5), 103106. https://doi.org/10.1360/zd-2013-43-6-1064.

Wang, C., Wu, X., \& Zhou, L. (2018, October). Analysis of Associated Economic Loss of Meteorological Disasters among the Belt and Road Typical Countries-Taking the China's Typhoon Rammasun in 2014 as an Example. In 8th Annual Meeting of Risk Analysis Council of China Association for Disaster Prevention (RAC 2018) (pp. 198-204). Atlantis Press.https://doi.org/10.2991/rac-18.2018.31.

Cheng Miao. (2007). The Research of Transportation Optimization Problem of Emergency Logistics under Public Emergency (Doctor's Thesis, Tongji University, Shanghai, China).

https://kns.cnki.net/KCMS/detail/detail.aspx?dbname=CDFD9908\&filename=2008125680.nh

Jing Li, Liyan Qi. (2015). Climatic characteristics of typhoon into interior Guangxi from different paths. Journal of catastrophology, 30(2), 115-119. https://doi.org/10.13995/j.cnki.11-1802/ts.2014.03.041.

Jing Li, Yijie Wu, Dongyan He. (2007). Comparative analysis of disaster causes of tropical cyclone Bilis and Prapiroon. Journal of Catastrophology, 22 (3), 72-76. https://doi.org/10.3969/j.issn.1000-811X.2007.03.017.

Liberatore, F., Ortuño, M. T., Tirado, G., Vitoriano, B., \& Scaparra, M. P. (2014). A hierarchical compromise model for the joint optimization of recovery operations and distribution of emergency goods in Humanitarian Logistics. Computers \& Operations Research, 42, 3-13. https://doi.org/10.1016/j.cor.2012.03.019.

Özdamar, L., Ekinci, E., \& Küçükyazici, B. (2004). Emergency logistics planning in natural disasters. Annals of operations research, 129(1), 217-245. https://doi.org/10.1023/B:ANOR.0000030690.27939.39.

Equi, L., Gallo, G., Marziale, S., \& Weintraub, A. (1997). A combined transportation and scheduling problem. European journal of operational research, 97(1), 94-104.https://doi.org/10.1016/S0377-2217(96)00085-9.

Desrochers, M., Lenstra, J. K., \& Savelsbergh, M. W. (1990). A classification scheme for vehicle routing and scheduling problems. European Journal of Operational Research, 46(3), 322-332.https://doi.org/10.1016/03772217(90)90007-X.

Nikoo, N., Babaei, M., \& Mohaymany, A. S. (2018). Emergency transportation network design problem: Identification and evaluation of disaster response routes. International journal of disaster risk reduction, 27, 7-20. https://doi.org/10.1016/j.ijdrr.2017.07.003.

Rodríguez-Espíndola, O., Albores, P., \& Brewster, C. (2018). Dynamic formulation for humanitarian response operations incorporating multiple organisations. International Journal of Production Economics, 204, 83-98. https://doi.org/10.1016/j.ijpe.2018.07.023.

Garrido, R. A., Lamas, P., \& Pino, F. J. (2015). A stochastic programming approach for floods emergency logistics. Transportation research part E: logistics and transportation review, 75, 18-31.https://doi.org/10.1016/j.tre.2014.12.002.

Zhan, S. L., Liu, N., \& Ye, Y. (2014). Coordinating efficiency and equity in disaster relief logistics via information updates. International Journal of Systems Science, 45(8), 1607-1621. https://doi.org/10.1080/00207721.2013.777490.

Tirado, G., Martín-Campo, F. J., Vitoriano, B., \& Ortuño, M. T. (2014). A lexicographical dynamic flow model for relief operations. International Journal of Computational Intelligence Systems, 7(sup1), 4557.https://doi.org/10.1142/9789814417747_0002.

Yun Yu, Zhiguang Chi, Zhao Fang, Sizhi Wei, Baoshen Li. (2014). Effects of typhoon Rammasun on banana production in Guangxi in 2014 and Suggestions on post-disaster production management. China Tropic Agriculture, (60):30-31. https://doi.org/10.3969/j.issn.1673-0658.2014.05.008.

Zhuo Huang, Xueping Liao. (2017). Impact assessment of typhoon "Sarika" on Guangxi in 2016. Journal of meteorological research and application, 38(1), 40-42. https://doi.org/10.3969/j.issn.1673-8411.2017.01.024. 